\title{
HOW ARABINOXYLANS MODIFY GLUTEN AND STARCH RELATED WHEAT FLOUR CHARACTERISTICS
}

\author{
A. Harasztos ${ }^{a *}$, G. Balázs ${ }^{a}$, P.N. CsöKE ${ }^{a}$, S. D’Amico ${ }^{\text {, }}$ \\ R. SCHÖNLECHNER ${ }^{\mathrm{b}}$ and S. TÖMÖSKÖZI ${ }^{\wedge}$ \\ ${ }^{a}$ Department of Applied Biotechnology and Food Science, Budapest University of Technology and Economics, \\ H-1111 Budapest, Szent Gellért tér 4. Hungary \\ ${ }^{\mathrm{b}}$ Department of Food Science and Technology, Institute of Food Technology, University of Natural Resources \\ and Life Sciences, Muthgasse 18, 1190 Wien. Austria
}

(Received: 22 July 2014; accepted: 18 November 2014)

\begin{abstract}
The positive nutritional impact of dietary fibres (DF) gives growing interest to their role in the formation of wheat product quality. Although we are getting closer to characterize the effect of DF on the end use quality, the roles of individual components are not well described yet. Arabinoxylans (AX) are the main compounds of wheat DF, therefore getting more knowledge about its behaviour in wheat based food systems, like dough or end products, could be useful from both theoretical and practical points of view. The aim of this study was to investigate the impact of the AX content on wheat flour quality using a dough model system provided by blends of flour and AX isolate. Rapid Visco Analyser (RVA) and recently developed micro Zeleny test were used for characterization of mixtures.

We found that although Zeleny values are basically related to protein-dependent quality, the addition of AX isolate has major impact on the sedimentation volume of flour. In the RVA studies we demonstrated that AX has influence not only on the viscosity values but also on the rate of viscosity change. The effect of AX addition was compared to that of starch addition and was corrected by the rate of dilution. The model system and the experimental method applied here can be suitable to separate the individual effects of non-starchy carbohydrates.
\end{abstract}

Keywords: arabinoxylan, wheat quality, RVA, micro-Zeleny

Arabinoxylans (AX) are the major components in dietary fibre, thus the understanding of their role in wheat flour quality is important. The limited knowledge available about this primarily includes the most widely used methods such as farinograph, mixograph, or alveograph, while further methods could also be helpful in this approach.

Sedimentation tests are known as simple but useful methods in the international practice of wheat quality determination. They characterize the swelling properties of flour in lactic acid (Zeleny test, AACC, 2000a) or sodium-dodecyl-sulphate (SDS) environment, which mainly depends on the gluten protein quantity and quality and are related to the end product quality, like loaf volume. There is little information on the role of carbohydrate components in the swelling process. CARVER and RAYBURN (1995) reported that starch-gluten interaction influences SDS sediment, and according to MAGHIRANG and co-workers (2006) it can possibly be affected by pentosans or damaged starch as well. Therefore, we find it necessary to consider the role of carbohydrate composition in the sedimentation measurements, especially when unusual carbohydrate components, like dietary fibre compounds, are present in considerable amounts.

\footnotetext{
* To whom correspondence should be addressed.

Phone: 36-1-4631153; e-mail: harasztos.anna@mail.bme.hu
} 
The methods mentioned above characterize a complex rheological behaviour of wheat dough system and are mainly determined by gluten complex, while carbohydrates play rather important role in viscosity. The effect of pentosans on this behaviour is generally characterized with capillary viscometers, dynamic measurements, and creep recovery tests (MA et al., 2012). However, some sophisticated viscometric methods, such as Rapid Visco Analyser (RVA) that is otherwise widely used to study viscous properties in carbohydrate rich food matrices, could also be useful for such purpose.

The pasting profile of wheat flour is primarily determined by starch properties, such as amylose-to-amylopectin ratio, chain length, and degree of branching (TESTER \& MORRISON, 1990), and among several other components, gluten strength also influences it (Fu et al., 2008). Studies available in limited number on some aspects of NSP role in pasting properties describe increase in RVA peak viscosity after addition of pentosan isolated from wheat flour (YIN \& WALKER, 1992). The same tendency is reported by SASAKI and co-workers (2000), adding NSP rich isolate to wheat starch, also revealing that this effect is modulated not only by the origin of NSP but also the amylose content of starch. Xylanolytic degradation of AX present in the sample is also an effective tool to study its effect, AHMAD and co-workers (2013) described negative correlation between degradation of AX and both viscosity peak and setback in amylographic studies.

Beside the discrete parameters traditionally evaluated in the RVA curves, considering the rich data generated by RVA analysis, recent studies evaluate also the first derivatives of the curves. This method of evaluation was effectively used for rice flour (MEADOws, 2002) and maize starch/amylose/amylopectin mixtures (JuHÁsZ \& SALGÓ, 2008). Derivative viscograms interpret the rate of viscosity changes during pasting and are helpful to recognize the fine details of the gelatinization process and to understand better the physical and chemical interactions between the starch components during gelatinization (JuHÁsz \& SALGó 2008). Recently, a feasibility study was also published about the use of derivatives and multivariate data methods, which allow better interpretation of the RVA profile, resulting in more information on the pasting properties (Cozzolino et al., 2012).

The aim of this study was to reveal the role of AX on some wheat flour characteristics and to investigate the suitability of micro methods (RVA, SediCom micro-Zeleny and microdough LAB) for this purpose.

\section{Materials and methods}

Wheat flour was kindly provided by the Agricultural Institute of the Hungarian Academy of Sciences. AX isolated from rye bran was produced at the University of Natural Resources and Life Sciences, Department of Food Science and Technology, Institute of Food Technology (38.08\% AX, all water extractable), on pilot scale (process described in MANSBERGER and coworkers, 2014). Unmodified wheat starch was purchased from Sigma (S5127).

AX-flour mix series was prepared so that WEAX concentrations remain in its typical range present in wheat flour. The WEAX concentration $(0.48 \%)$ of the wheat flour used was raised with $0.50 ; 1.00 ; 1.50 ; 2.00$ and $2.50 \%$ in the mixtures. Starch-flour mix series was prepared with $1.30 ; 2.59 ; 3.89 ; 5.18$; and $6.48 \%$ increment of starch content, which is calculated as follows: Increment of starch [\%]=Increment of WEAX[\%]/WEAX in isolate[\%]. Micro-dough LAB (Perten, Newport Scientific) was used for homogenization: 4 grams of powder mixture were mixed for $6 \mathrm{~min}$. 
AX contents were determined by a slightly modified GC method of GeBRUERS and coworkers (2009): hydrolysis time was 1 hour and dichloromethane was used for phase separation. Alditol acetates were separated on 50\% phenyl-methylpolysiloxane column (Perkin Elmer Elite17) with GC-FID (Perkin Elmer Clarus500). Injector and detector were maintained at $300{ }^{\circ} \mathrm{C}$, while the column temperature was tempered at $250^{\circ} \mathrm{C}$.

Viscosity parameters were determined with Rapid Visco Analyser (Series4 RVA, Perten Instruments) using General Pasting Method (AACC, 2000b) as specified by the manufacturer. Derived curves were evaluated as introduced by JuHÁsz and SALGó (2008). Pearson's correlation coefficients were calculated at every data point between the viscosity values of the single curves and the corresponding AX concentrations of the samples.

For micro Zeleny tests SediCom System ${ }^{\circledR}$ (Lab-Intern Ltd.) was performed as indicated by the manufacturer. Results obtained by micro-Zeleny correlate well with those obtained by standard AACC method (AACC, 2000a; TöмösKöZI et al., 2009).

All measurements were carried out at least in triplicates. Wilcoxon-test, Pearson's linear correlation coefficients and their significance testing were performed with Statistica 9 software (StatSoft Inc.).

\section{Results and discussion}

\subsection{Homogeneity test and suitability check of analytical methods}

Homogeneity of the flour/AX isolate mixtures was tested by measuring AX content of 3 mixtures and sampling from 3 different places from each. Relative standard deviations (RSD\%) of WEAX content within the mixtures were acceptable regarding the uncertainty of the GC measurement that is typically below $5 \%$ (Table 1).

AX content of the mixtures was verified: Wilcoxon-test supports that there is no significant difference between calculated and measured AX content (Table 1).

\begin{tabular}{lcc}
\multicolumn{3}{c}{ Table 1. Homogeneity testing and verification of AX content } \\
\hline Flour & $\begin{array}{c}\text { RSD\% of AX content } \\
\text { within a sample } \\
(* \text { difference\%) }\end{array}$ & $\begin{array}{c}\text { Difference\% } \\
\text { (measured-calculated) }\end{array}$ \\
Blend1 & 0.63 & - \\
Blend2 & 7.30 & 5.65 \\
Blend3 & 13.20 & 5.89 \\
Blend4 & 12.20 & 7.52 \\
Blend5 & $6.39^{*}$ & 0.33 \\
\hline
\end{tabular}

Repeatability of RVA measurement is given as the RSD\% of parameters in at least three different measurements. RSD\% in mixtures was only slightly higher than that reported in flours (JuHÁsz \& SALGÓ, 2006) and was above $6 \%$ only in case of the breakdown that provided the highest error also in pure flour samples (Table 2). RSD\% of Zeleny measurements in mixtures remained under $5 \%$. 


\begin{tabular}{lcc}
$\begin{array}{l}\text { Table 2. Repeatability of RVA parameters in AX-flour mixtures compared to those reported } \\
\text { by JuHÁsZ and SALGó (2006) }\end{array}$ \\
$\begin{array}{l}\text { RSD\% } \\
\text { AX-flour mixture }\end{array}$ & $\begin{array}{c}\text { RSD\% } \\
\text { Wheat flour } \\
\text { (JuHÁsz and SALGÓ, 2006) }\end{array}$ \\
\hline Peak viscosity (cP) & 4.31 & 0.53 \\
Trough (cP) & 5.18 & 3.07 \\
Breakdown (cP) & 6.25 & 5.20 \\
Final viscosity (cP) & 3.43 & 1.74 \\
Setback (cP) & 1.69 & 2.62 \\
Peak time (min) & 1.06 & 1.22 \\
Pasting temperature $\left({ }^{\circ} \mathrm{C}\right)$ & 0.04 & 0.65 \\
\hline
\end{tabular}

Based on the results shown above, homogeneity of powder mixture, recovery value of AX addition, and repeatability of RVA results have proved to be satisfactory for further analyses.

\subsection{Evaluation of RVA profiles}

Although the RVA profile is associated with starch characteristics, there is enough reason to assume that AX has an impact on these despite its low concentration. All measured viscosity parameters of AX-flour mixtures showed constant increase in all cases with a jump at $2.5 \%$ WEAX (Fig. 1). The increase of peak viscosity is in agreement with the results of SASAKI and co-workers (2000) using NSP rich isolate, but in contrast to those of YIN and WALKER (1992) using pentosans originating from wheat flour. Such discrepancies are supposedly due to the fact that functional properties of WEAX are strongly associated with its origin, molecular weight, and degree of branching (REVANAPPA et al., 2010).

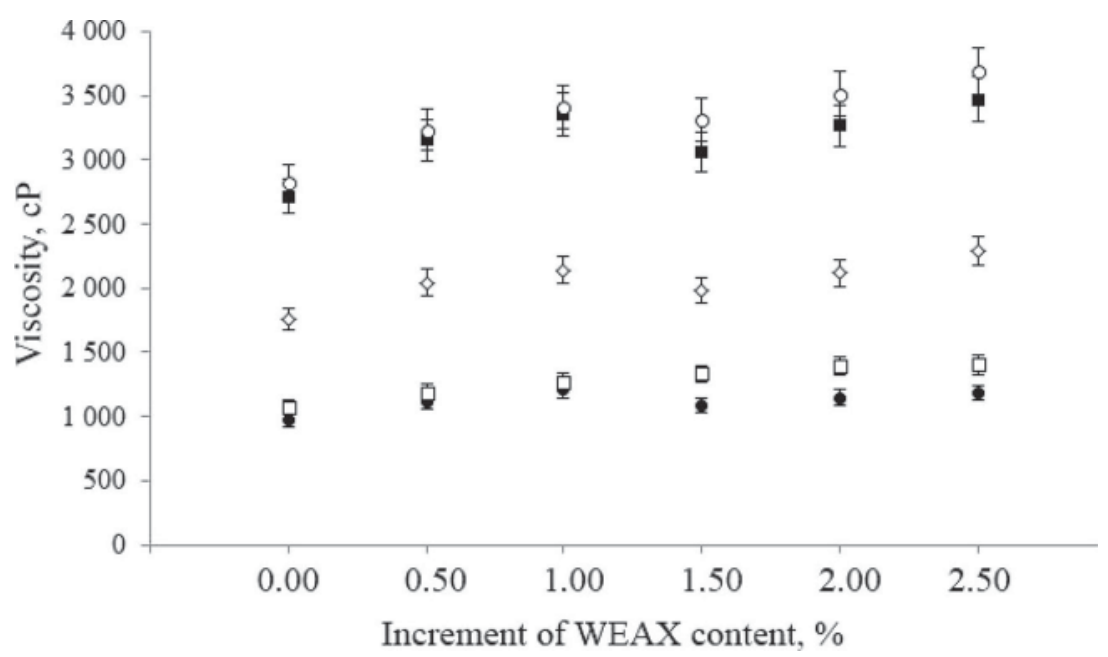

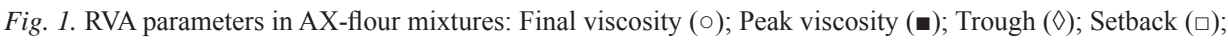
Breakdown $(\bullet)$ 
Samples of higher WEAX contents showed conspicuously higher viscosity starting around the gelatinization phase and lasting up to the end of the curve (Fig. 2). As described earlier, at each data point one correlation coefficient was calculated between 6 viscosity values of the 6 samples and the corresponding WEAX contents. These correlation data can be interpreted as a function of time, one for the whole mix series describing the correlation between WEAX content and viscosity. This function highlights a short region around 260$330 \mathrm{~s}$ that shows negative correlation with the WEAX content in contrast to the unequivocal positive correlation in the rest of the viscogram (Fig. 2).

Taking a closer look at the derivative curves (Fig. 3), this region of negative correlation can be observed clearly: it appears as a small peak, a 'shoulder'. Correlation function in the case of derivative curves represents the correlation between WEAX content and rate of viscosity changes. This means that the pasting process at its beginning phase was slowered down by the presence of WEAX isolate.

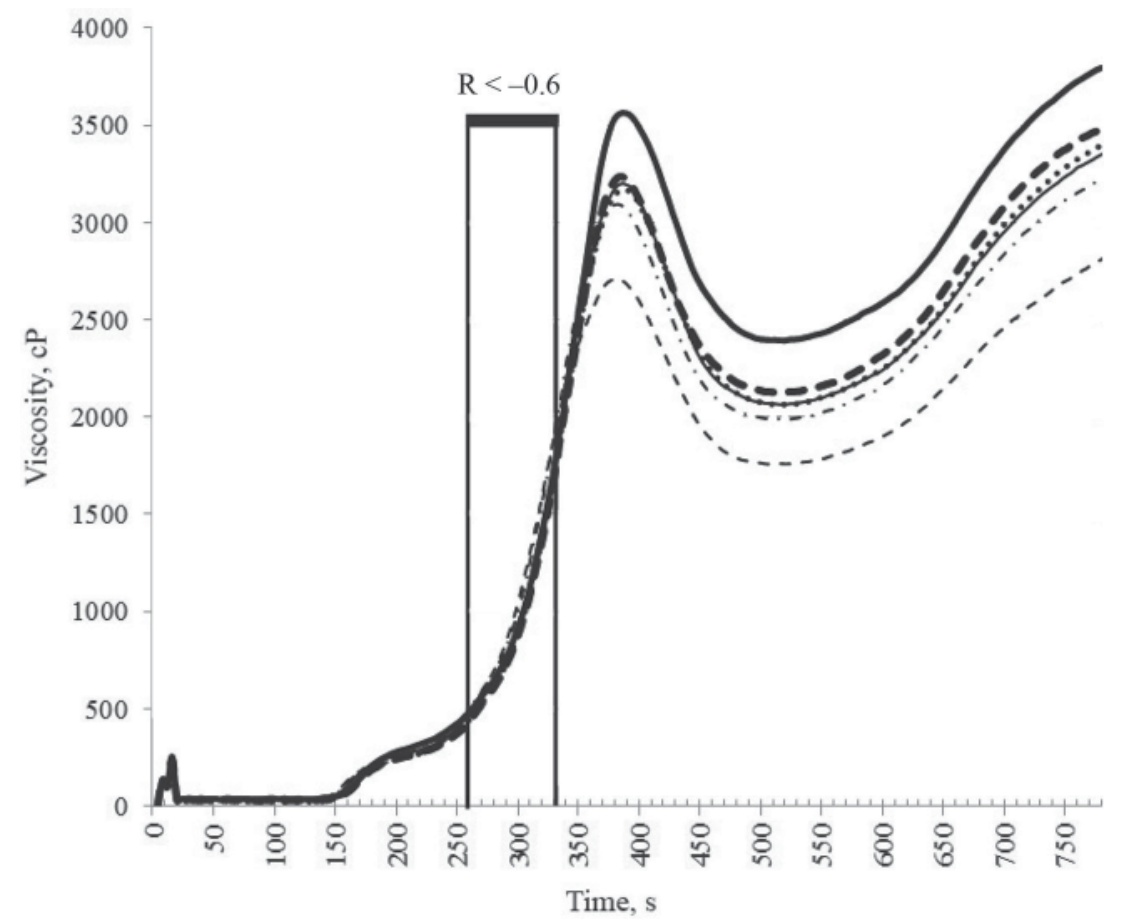

Fig. 2. RVA curves in AX-flour mixtures; Pearson's correlation coefficients (R) between viscosity and AX content are shown. Wheat flour $(----) ;+0.5 \%(-\cdot-\cdot-) ;+1.0 \%(-) ;+1.5 \%(\cdots),+2.0 \%(--),+2.5 \%(-)$

The derivative curves and the correlation function revealed some further details. Getting nearer to peak time in the hot paste region, the correlation between WEAX content and rate of viscosity change turned into positive, indicating that peak viscosity is not only higher but is also reached faster at higher WEAX contents (Fig. 3). In the holding period due to the total dispersion of starch granules (400-500 s) the drop of viscosity occurred also faster at the presence of added WEAX, indicating that the gel structure has higher sensitivity for disintegration when heated and stirred. Rate of viscosity raise at the region of retrogradation 
(620-720 s) was also higher for samples with increased WEAX content. It seemed that WEAX would help in faster restabilization of the gel structure. These results support the observation of SivAm and co-workers (2010), that WEAX plays role in starch retrogradation and complete it by assuming that pentosans influence primarily the rate of viscosity changes during the pasting process. We cannot rule out the possibility that this effect is also achieved through WEAX-gluten interaction, since gluten strength itself also affects pasting properties.

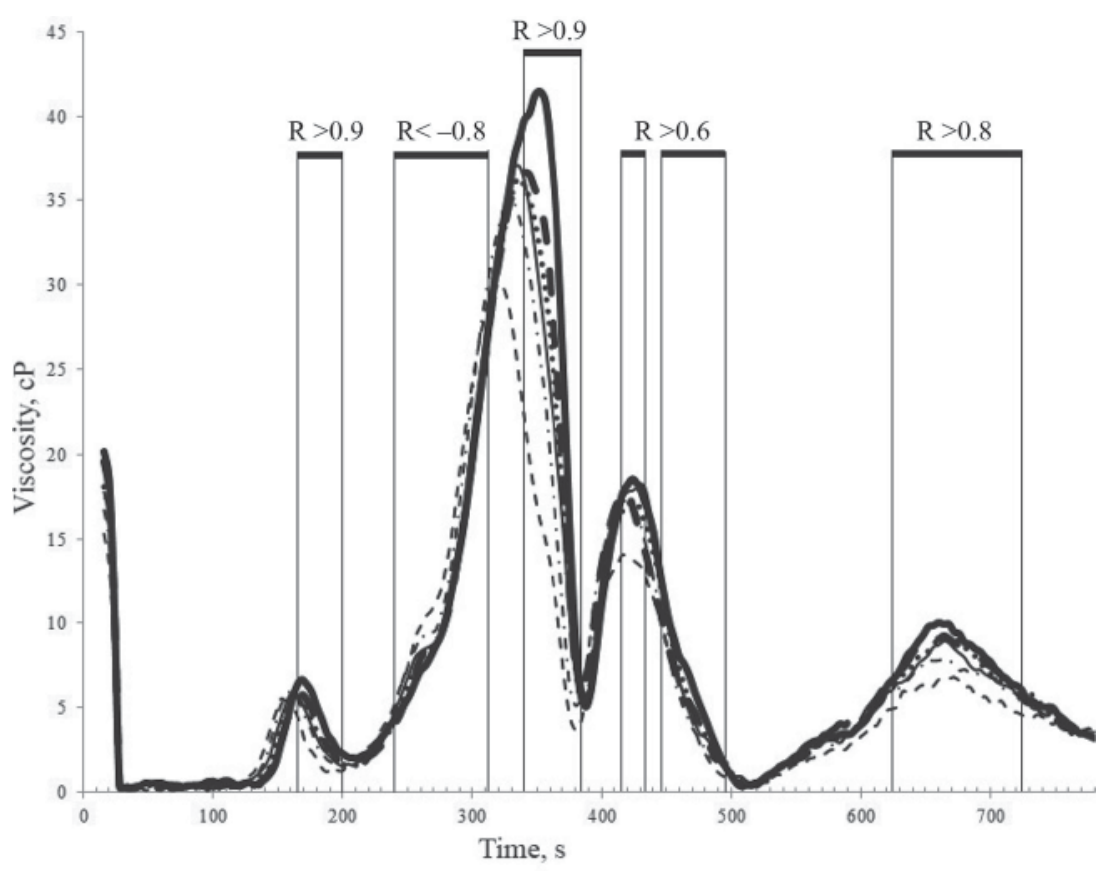

Fig. 3. RVA derivatives in AX-flour mixtures; Pearson's correlation coefficient (R) between rate of viscosity and AX content are shown. Wheat flour (----); +0.5\% (-.-.-); $+1.0 \%(-) ;+1.5 \%(\cdots),+2.0 \%(--),+2.5 \%(-)$

To exclude the potentially misleading effect of diluting the wheat flour, another mix series was also investigated, where starch isolate was added in the same amounts as formerly the AX isolate. RVA curves of these mixtures did not show any significant change that could be related to the starch content of the samples (Fig. 4). In other words, while increasing starch content on a wider scale would clearly have significant effect on RVA profile, change of its amount at such a low concentration range does not have any significant impact comparabale to that caused by a change of WEAX to the same extent. This reveals that the observed effect may not be attributed to the 'dilution effect' meaning decrease in starch content but to the presence of WEAX isolate. 


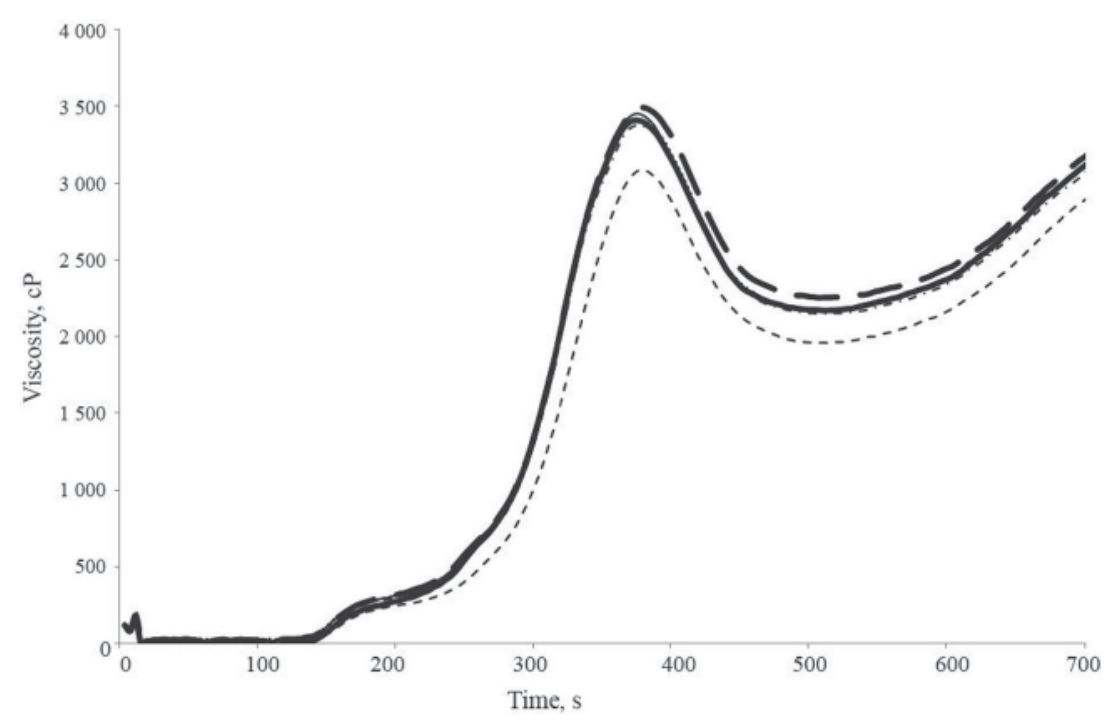

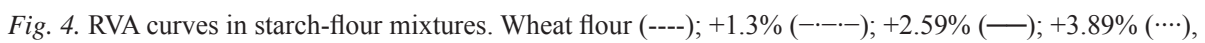
$+5.18 \%(-\longrightarrow),+6.48 \%(-)$

\subsection{Sedimentation properties}

The interpretation of sedimentation properties in literature as a function of gluten quality does not consider presence of fibre components or any NSP carbohydrates. However, the fact that pentosans can play a role in the hydration process of flour-to-dough systems and can interfere with gluten, implies that they should be taken into account. Our results (Fig. 5) show significant drop of Zeleny sedimentation volumes at higher WEAX content. The addition of starch in the same concentration range also decreased the Zeleny number but to a significantly smaller extent. A possible interpretation would be an indirect effect of water extractable pentosans (LABAT et al., 2001), caused by their ability to form a network limiting the movement of gluten in proteins and formation of larger aggregates, resulting in lower sedimentation volume. Further analyses with WEAX isolate of higher purity would be necessary to rule out that its protein content is also involved in the observed effect, although this consists mainly of smaller proteins (MANSBERGER et al., 2014). 


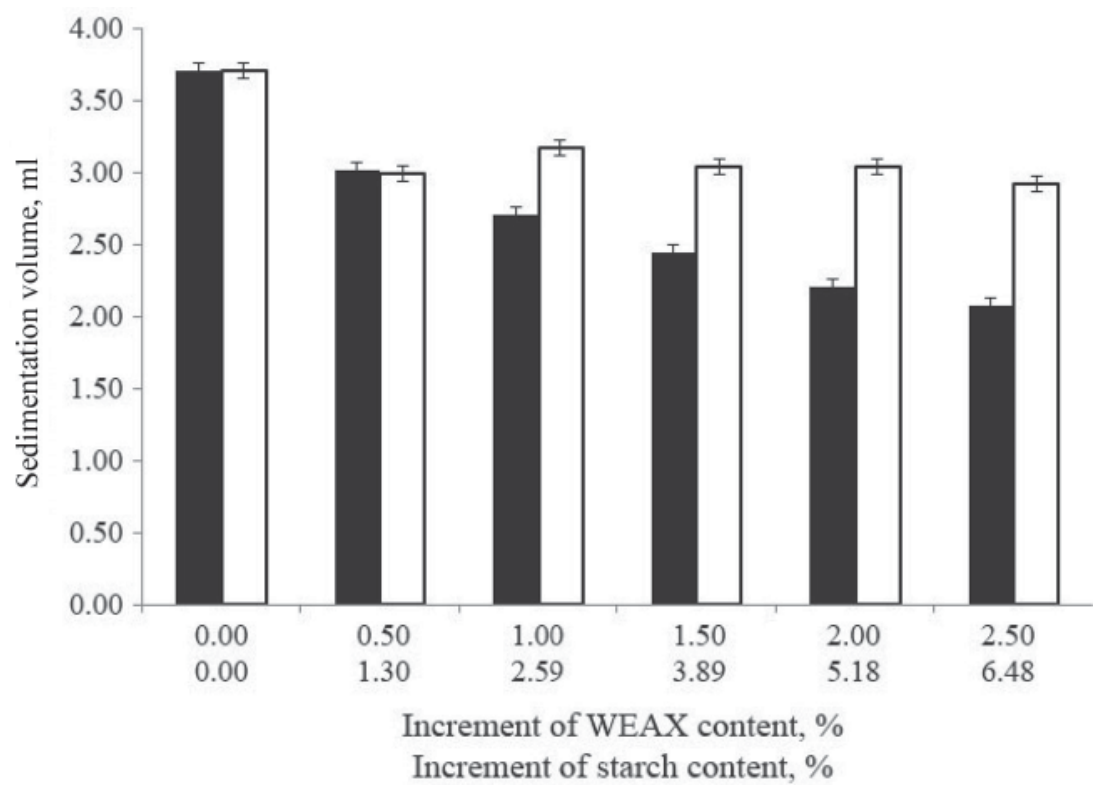

Fig. 5. Zeleny sedimentation volumes in AX-flour (匹) and starch-flour ( $\square$ ) mixtures

\section{Conclusions}

Our results show that the addition of WEAX in a concentration range that is typical in wheat flour has a significant influence on the rate of viscosity changes, by slowing down the gelatinization but accelerating pasting and retrogradation. Swelling characteristics despite their primary dependence on protein quality also appear to be influenced by added WEAX. At this stage of research we can only assume that fibre components such as WEAX modify the formation of protein-carbohydrate complex and its properties.

This study demonstrates that the interpretation of both the sedimentation and pasting processes may take into account the presence of arabinoxylans. We have also shown that micro-analytical methods can be effective tools for investigating the role of dietary fibre components in wheat flour quality.

This work is connected to the scientific programs of OTKA-CK80334 and TÉT_10-1-2011-0731 projects, and is supported by the New Hungary Development Plan (TÁMOP-4.2.1/B-09/1/KMR-2010-0002).

\section{References}

AACC (2000a): Sedimentation test for flour. No. 56-60.

AACC (2000b): General pasting method for wheat or rye flour or starch using the Rapid Visco Analyser. No. 76-21. Ahmad, Z., Butt, M.S., Ahmed, A. \& Khalid, N. (2013): Xylanolytic modification in wheat flour and its effect on dough rheological characteristics and bread quality attributes. J. Korean Soc. Appl. Bi., 56, 723-729.

CARver, B.F. \& RAYBurn, A.L. (1995): Comparison of related wheat stocks possessing 1B or T1BL/1RS chromosomes: Grain and flour quality. Crop Sci., 35, 1316-1321. 
Cozzolino. D., Allder, K., Roumeliotis, S. \& Eglinton, J. (2012): Feasibility study on the use of multivariate data methods and derivatives to enhance information from barley flour and malt samples analysed using the RVA. J. Cereal Sci., 56, 610-614.

Fu, L., Tian, J., Sun, C. \& Li, C. (2008): RVA and farinograph properties study on blends of resistant starch and wheat flour. Agr. Sci. China, 7, 812-822.

Gebruers, K., Courtin, C.M. \& Delcour, J.A. (2009): Quantification of arabinoxylans and their degree of branching using gas chromatography. -in: SHEwry, P.R. \& WARD, J.L. (Eds) Healthgrain methods, analysis of bioactive components in small grain cereals. AACC International, St. Paul, Minnesota, USA, pp. 177-189.

JuHÁsz, R. \& SALGó, A. (2006): A gyors viszko-analizátoros technika alkalmazási lehetőségei (Potential applications of the RVA technique). Élelmiszervizsgálati Közlemények, 52(4), 208-215.

JuHÁsz, R. \& SALGÓ, A. (2008): Pasting behavior of amylose, amylopectin and their mixtures as determined by RVA curves and first derivatives starch. Stärke, 60(2), 70-78.

Labat, E., Morel, M.H. \& Rouau, X. (2001): Effect of laccase and manganese peroxidase on wheat gluten and pentosans during mixing. Food Hydrocoll., 15, 47-52.

MA, F., Xu, S., Xu, M. \& GuO, X. (2012): The influence of water soluble pentosan on viscoelasticity of gluten. J. Food Eng., 111, 166-175.

Maghirang, E.B., Lookhart, G.L., Bean, S.R., Pierce, R.O., Xie, F., Caley, M.S., Wilson, J.D., Seabourn, B.W., Ram, M.S., Park, S.H., Chung, O.K. \& Dowell, F.E. (2006): Comparison of quality characteristics and breadmaking functionality of hard red winter and hard red spring wheat. Cereal Chem., 83, 520-528.

Mansberger, A., D’Amico, S., Novalin, S., Schmidt, J., Tömösközi, S., Berghofer, E. \& Schoenlechner, R. (2014): Pentosan extraction from rye bran on pilot scale for application in gluten-free products. Food Hydrocoll., 35, 606-612.

Meadows, F. (2002): Pasting process in rice flour using RVA curves and first derivatives. Cereal Chem., 79, 559562.

Revanappa, S.B., NAndini, C.D. \& Salimath, P.V. (2010): Structural characterization of pentosans from hemicellulose $\mathrm{B}$ of wheat varieties with varying chapatti making quality. Food Chem., 119, 27-33.

SASAKI, T., YASUI, T. \& MATSUKi, J. (2000): Influence of non-starch polysaccharides isolated from wheat flour on the gelatinization and gelation of wheat starches. Food Hydrocoll., 14, 295-303.

Sivam, A.S., Sun-Waterhouse, D., Quek, S. \& Perera, C.O. (2010): Properties of bread dough with added fiber polysaccharides and phenolic antioxidants: a review. J. Food Sci., 75(8), 163-174.

Tester, R.F. \& Morrison, W.R. (1990): Swelling and gelatinisation of cereal starches. I. Effects of amylopectin, amylose and lipids. Cereal Chem., 67, 551-557.

Tömösközi, S., Nádosi, M., Balázs, G., Gergely, Sz., Cavanagh, C., Morgounov, A., Salgó, A. \& Békés, F. (2009): Revival of sedimentation value - method development, quality prediction and molecular background. Proceedings of the 10th International Gluten Workshop. Edited by INRA, Paris, France.

Yin, Y. \& WALKER, C.E. (1992): Pentosans from gluten-washing waste-water - isolation, characterizations, and role in baking. Cereal Chem., 69(6), 592-596. 